\title{
Entre derecho y realidad: antropología y territorios indígenas amazónicos en un futuro próximo*
}

Entre le droit et la réalité : l'anthropologie et les territoires autochtones

d'Amazonie dans un avenir proche

Between rights and reality: Anthropology and Amazonian indigenous territories in the near future

\section{Alexandre Surrallés}

\section{(2) OpenEdition}

\section{Journals}

Edición electrónica

URL: http://journals.openedition.org/bifea/2789

DOI: $10.4000 /$ bifea.2789

ISSN: 2076-5827

\section{Editor}

Institut Français d'Études Andines

\section{Edición impresa}

Fecha de publicación: 1 abril 2009

Paginación: 29-45

ISSN: 0303-7495

\section{Referencia electrónica}

Alexandre Surrallés, « Entre derecho y realidad: antropología y territorios indígenas amazónicos en un futuro próximo* ", Bulletin de l'Institut français d'études andines [En línea], 38 (1) | 2009, Publicado el 01 octubre 2009, consultado el 17 noviembre 2020. URL : http://journals.openedition.org/bifea/2789 ; DOI : https://doi.org/10.4000/bifea.2789

\section{(c) $(1) \odot$}

Les contenus du Bulletin de l'Institut français d'études andines sont mis à disposition selon les termes de la licence Creative Commons Attribution - Pas d'Utilisation Commerciale - Pas de Modification 4.0 International. 


\title{
Entre derecho y realidad: antropología y territorios indígenas amazónicos en un futuro próximo*
}

\author{
Alexandre Surrallés**
}

\begin{abstract}
Resumen
La territorialidad de los pueblos indígenas ha sido, sin duda, uno de los temas más importantes de la antropología amazónica y lo seguirá siendo en las décadas por venir. Los intereses multinacionales crecientes en los recursos naturales, el éxodo rural y la movilidad de la población, las revisiones de las políticas estatales de la gestión de los espacios amazónicos, las mutaciones de la percepción indígena sobre su entorno, entre otros factores de cambio, se confrontan hoy a una situación internacional que, con la reciente Declaración de las Naciones Unidas sobre los derechos de los pueblos indígenas, nunca había sido tan favorable para sus derechos colectivos. En este artículo se analizará, a partir del caso peruano, una de las problemáticas resultantes de esta compleja situación: el conflicto entre el derecho al territorio de los pueblos indígenas y las políticas de extracción de recursos en sus tierras, promovidas por el Estado. Todo ello a la luz de los avances realizados en derecho internacional, a fin de vislumbrar el futuro de la antropología amazónica en materia de territorio.
\end{abstract}

Palabras clave: territorio, Amazonía, Perú, pueblos indígenas, derechos humanos, explotación petrolera

\footnotetext{
Este artículo es una versión extendida de la conferencia presentada en la mesa «Perspectivas en Antropología amazónica», Ilevada a cabo en el Centro Cultural de la PUCP (Lima) el 17 de septiembre del 2008, con motivo de los actos conmemorativos por el 60 aniversario del Instituto Francés de Estudios Andinos (IFEA). Quisiera agradecer a Jean-Pierre Chaumeil por la invitación a participar en la mesa, a los participantes por sus comentarios y al IFEA, no solo por hacerme partícipe de su aniversario sino por todas las veces que, a lo largo de estos últimos quince años, me han acogido en mis viajes de estudios al Perú. Desde mis primeras estancias como doctorando, los diferentes directores como los colaboradores permanentes del Instituto, me han reservado siempre una acogida calurosa que, de regreso a París, ha sido motivo de añoranza y de entrañable recuerdo.

** Laboratoire d'anthropologie sociale, CNRS, Collège de France. 52 rue du Cardinal Lemoine. 75005 París, France. E-mail: alexandre.surralles@college-de-france.fr
} 


\title{
Entre le droit et la réalité : l'anthropologie et les territoires autochtones d'Amazonie dans un avenir proche
}

\section{Résumé}

La territorialité des peuples autochtones a été sans aucun doute l'un des sujets les plus importants de l'anthropologie amazonienne et le restera dans les décennies à venir. Les intérêts multinationaux pour les ressources naturelles, l'exode rural et la mobilité de la population, la révision des politiques étatiques de gestion des territoires amazoniens, l'évolution de la perception de leur environnement par les autochtones, entre autres facteurs de changement, font face maintenant à une situation internationale qui, suite à la récente Déclaration des Nations Unies sur les droits des peuples autochtones, n'a jamais été aussi favorable pour leurs droits collectifs. Ce texte analysera, à partir du cas péruvien, l'un des problèmes résultant de cette situation complexe : le conflit entre le droit au territoire des peuples autochtones et les politiques d'exploitation des ressources naturelles de leurs terres promues par le gouvernement actuel. Ceci à la lumière des progrès du droit international et avec l'intention d'entrevoir l'avenir de l'anthropologie amazonienne du territoire.

Mots clés : territoire, Amazonie, Pérou, peuples autochtones, droits humains, exploitation pétrolière

\section{Between rights and reality: Anthropology and Amazonian indigenous territories in the near future}

\begin{abstract}
The territoriality of indigenous peoples has been one of the most important topics of Amazonian anthropology and it will remain so in the next years. The growing multinational interests in natural resources; rural migration and population mobility; the revisions of administration policies for the management of the Amazon area; the mutations of the indigenous perception on their environment among other factors of change, confront now an international situation that, with the recent United Nations Declaration on the Rights of Indigenous Peoples, had never been so favorable for their collective rights. This text will explore, based on the Peruvian case, one of the problems resulting from this complex situation: the conflict between the right to the territory of indigenous peoples and projects of natural resource exploration and production on their land promoted by the State. This will be viewed in the light of progress in international law with the goal of foreseeing the future of Amazonian anthropology in regards to the issue of territory.
\end{abstract}

Key words: territory, Amazon, Peru, indigenous peoples, human rights, oil production

\section{INTRODUCCIÓN}

Afirmar que la territorialidad continuará siendo uno de los temas más importantes de la antropología amazónica de los pueblos indígenas parece obvio dada la tensa situación que vive la selva peruana, después del intento de revisión por parte del gobierno de la legislación que había permitido, hasta hoy, un principio de reconocimiento de sus tierras1.

1 En agosto de 2008 el gobierno intenta devaluar el contenido de la Ley de Comunidades Nativas y Campesinas con dos decretos legislativos (1015 y 1073), conocidos como la «ley de la selva». Esto produjo una movilización histórica de los pueblos indígenas de la Amazonía peruana, por lo que el Congreso decide derogarla citando el Convenio 169 de la OIT por primera vez en la cámara legislativa: un triunfo para la Asociación Interétnica 
Ahora bien, el tema de la territorialidad es relevante también en la actualidad porque desborda ampliamente el de la demarcarción, la tenencia y los derechos que la amparan. En décadas pasadas el territorio indígena era concebido como una superficie poligonal que se podía reproducir en un mapa, que circunscribía el espacio necesario para la subsistencia de la población y que debía titularse a su nombre. Hoy en día, en contraste, la antropología del territorio tiene en cuenta el conjunto de las relaciones que un pueblo indígena establece con el entorno y, muy especialmente, su propia percepción, que puede distar mucho de la visión simplista de una superficie de tierra necesaria para la alimentación². En el campo de la antropología del territorio actual se trata de todo aquello relacionado con los procesos de intercambio entre humanos y medio ambiente para satisfacer las necesidades productivas y reproductivas de una colectividad social pero en función de sus prioridades culturales. También de la descripción de los vínculos parentales, sociales y políticos que se establecen en el seno de un grupo étnico, para aprovechar adecuadamente las posibilidades que ofrece la biosfera circundante y la historia de su presencia, en las áreas que ocupan o han ocupado, establecida tanto a partir de pruebas documentales como de la historia oral. La antropología interesada en el territorio comprende de igual forma la llamada ecología simbólica, es decir la percepción autóctona de los factores bióticos y abióticos del medio, alejada a menudo de la dualidad convencional naturaleza-cultura, bien que permite a la población satisfacer cotidianamente las necesidades no solo materiales sino aquellas denominadas metafísicas por la filosofía o espirituales por la religión. Se interesa igualmente por analizar la concepción indígena de la persona la cual, irreducible a la idea de humanidad, individuo o incluso a la dualidad cuerpo-mente, supone un desafío no solo a la jurisprudencia existente sobre el derecho territorial, sino también a la noción misma de sujeto de derecho. Podríamos, por último, citar las condiciones sociales, políticas y jurídicas, individuales y colectivas, de la ocupación espacial, así como los procesos, expectativas, transformaciones y los conflictos que suscita. El territorio engloba todavía otros aspectos, aunque los enumerados son probablemente los más importantes.

Estas perspectivas sobre el mismo fenómeno encuentran en la selva una situación que se renueva sin cesar, con los intereses multinacionales crecientes en esta región, el éxodo rural y la movilidad de la población indígena, las revisiones de las políticas estatales de la gestión de los espacios amazónicos o las mutaciones culturales producidas por la globalización. Sin embargo, mi convicción de la importancia futura de este tema para la antropología amazónica viene, sobre todo, de la acusada presión a que están sujetas las cuestiones territoriales, derivada del interés creciente que suscitan los recursos naturales proporcionados por los bosques tropicales húmedos y su subsuelo. Las facilidades que proporcionan los Estados para su explotación frente al derecho de los pueblos indígenas a su territorio y el evidente conflicto de intereses resultante, completan el panorama. Esta situación no es nueva pero se confronta con una legislación internacional que, con la reciente Declaración de las Naciones Unidas sobre los derechos de los pueblos indígenas, nunca había sido tan favorable para los derechos colectivos de estos últimos. Centrado en la Amazonía peruana, este texto analizará las problemáticas resultantes de esta compleja situación y sugerirá unas líneas de reflexión para la antropología venidera.

de Desarrollo de la Selva Peruana (AIDESEP) que encabezó la movilización y un revés, sin precedentes en la legislatura, para el Presidente.

2 El propósito y las distintas contribuciones del libro que he coeditado con Pedro García Hierro (2004) analiza esta evolución y presenta algunas reflexiones y experiencias concretas en este sentido. Véase también el artículo de Richard Chase Smith (2006a). 


\section{LOS PUEBLOS INDÍGENAS Y LA PROPIEDAD DE LA TIERRA EN AMAZONÍA}

Los pueblos indígenas de toda la Amazonía se han organizado en torno al reclamo de su derecho a salvaguardar sus espacios territoriales. Estos procesos varían según los países de la cuenca, pero tienen en común una profundidad histórica similar de más de tres decenios. En cada uno de los países, estos procesos han sido largos y complicados pero, en términos globales, se puede decir que los pueblos indígenas han logrado ciertos avances. Sin embargo, estos avances se han producido cuando la selva ocupaba un espacio relativamente marginal. Hoy en día esto puede estar cambiando. Los recursos naturales, en especial la madera, los minerales y sobre todo el petróleo — en un periodo de grandes oscilaciones de su precio en el mercado internacional, con el barril de Brent triplicando su valor en meses pasados antes de caer drásticamente-; la biodiversidad que ofrece la selva, especialmente la de los países andinos, para las industrias de biotecnología; la incidencia de los bosques tropicales en la meteorología del planeta en un momento de cambio climático; incluso la importancia del agua dulce en un futuro donde ésta puede ser escasa, son algunos elementos que permiten presagiar que las selvas se convertirán rápidamente en zonas de gran interés económico - y por lo tanto estratégico-, pues los «productos» ofrecidos devendrán bienes preciosos. Todo esto no es nuevo, por supuesto, pero es muy posible que se intensifique en los próximos años si la presente coyuntura económica se mantiene, con una división del trabajo mundial donde algunos países amazónicos son relegados a proveedores de materias primas.

En el Perú, decir que estamos entrando en una fase de grandes cambios en relación a la territorialidad indígena puede parecer paradójico, dado que el largo proceso de titulación de tierras, iniciado en la década de 1970 — al amparo de la Ley de Comunidades Nativas y Campesinas promovida por la dictadura militar de Velasco Alvarado-, parecería haber culminado con un cierto éxito, permitiendo a estas poblaciones el goce de cierta seguridad territorial. Es cierto que cuando se redactó la primera versión de la ley en 1974 no se tenía un conocimiento preciso de la realidad amazónica, por ello se trasladó el modelo de comunidad forjado en la costa y en la sierra a la selva, con consecuencias importantes y no siempre beneficiosas, como trataré más adelante. Sin embargo, en la época en que se formuló, no se podía pedir más, pensarían seguramente los indígenas y sus organizaciones. Basta recordar que, incluso hoy, tiene más fácil acceso a la propiedad cualquier individuo, recién llegado a la zona, que cerque un pasto en las orillas del Marañón para cuatro cabezas de ganado o los «invasores» de terrenos periféricos de las ciudades, que un pueblo indígena aún en condiciones de demostrar un vínculo prehispánico con el área ocupada. Por ello, desde mediados de la década de los setenta hasta hace poco — antes que este gobierno paralizara todo proceso de titulación-, se han titulado cientos de comunidades nativas y otras áreas protegidas a nombre de los pueblos indígenas. Las organizaciones indígenas y AIDESEP, en particular, han promovido las campañas más importantes de inscripción y legalización de territorios comunales a través de un trabajo de cogestión con el Ministerio de Agricultura. El balance en términos estrictamente cuantitativos parece positivo. Así, el Directorio de Comunidades Nativas del Ministerio de Agricultura arroja la cifra de aproximadamente 1500 comunidades nativas, lo que significa una extensión territorial de unas 10503888 hectáreas tituladas. Hay que añadir unas 2 799,901 hectáreas de cinco reservas territoriales (una forma de titulación sujeta a confirmación que está contemplada en la ley), así como unas cuantas comunidades nuevas —y ampliaciones de las ya existentesen la provincia de Datem del Marañón y en las orillas del río Corrientes, siempre en Loreto, tituladas recientemente. 
Se podrían también considerar como superficies tituladas las reservas comunales que ocupan casi dos millones de hectáreas, además de cinco propuestas a futuro de reservas territoriales y siete de reservas comunales (con expedientes listos y presentados ante el Estado), y algunas comunidades más por titular. Este proceso ha tenido como resultado cuatro tipos muy distintos de situaciones para las poblaciones indígenas. Unos pueblos indígenas han conseguido espacios territoriales que abarcan partes medulares de sus territorios étnicos 4 y que, por lo mismo, permiten una buena gestión territorial, a pesar de la división de la propiedad en una multiplicidad de pequeños pedazos de áreas, a modo de archipiélago. Otros pueblos indígenas han conseguido recuperar sus territorios históricos, pero dando por perdidas zonas relevantes, como las áreas cercanas a zonas urbanas, bocas de río y primeras líneas de carreteras de penetración, debido al avance del frente colonial. Algunos pueblos se encuentran en una combinación de las dos situaciones anteriores: por una parte, el control de espacios considerables de sus territorios tradicionales en zonas poco accesibles, pero manteniendo solo algunas parcelas en aquellas partes de su territorio presionadas por el frente de colonización. Existen, por último, pueblos que han conseguido titular reservas territoriales extensas en zonas remotas de la selva gracias a una situación de contacto esporádico o de aislamiento voluntario5.

Pensar que ha llegado a la Amazonía el «fin de la historia» para los indígenas presupone que, en términos generales, la titulación de las tierras indígenas está muy avanzada y que se ha consolidado el derecho sobre el territorio con más de 10 millones de hectáreas tituladas a su nombre. Esta perspectiva olvida, sin embargo, dos cosas: que la topografía resultante de estas tierras tituladas no corresponde con los territorios históricamente ocupados por los pueblos indígenas — ni en la forma, ni en la extensión, ni en la calidad — y que la legitimidad sobre unos espacios de tierra no asegura necesariamente el ejercicio real del derecho de tenencia. En efecto, las tierras indígenas legitimadas durante estos años no lo son en forma, cantidad y calidad suficiente. En muchos casos, no se puede afirmar que estas superficies legitimadas sean territorios, en el sentido de un espacio que permita el uso integral tanto de sus recursos materiales como inmateriales. Por la interpretación de la Ley de Comunidades Nativas y Campesinas, la topografía de este proceso, de más de 20 años de titulación, es una constelación de espacios sin que la continuidad territorial sea respetada. Pequeños polígonos cuya área es determinada en función de la demografía del colectivo, definido por la comisión encargada de titular a su paso por los ríos. Estos polígonos (que son los espacios comunales) segmentan el territorio en base a una realidad que no tiene en cuenta la fluidez social y la gran movilidad residencial de la mayoría de las sociedades indígenas amazónicas, al interior de su espacio geográfico. Además, si comparamos las tierras efectivamente tituladas con los espacios que ocupan los diferentes pueblos indígenas, en base a criterios de orden lingüístico por ejemplo — es decir, los espacios donde se habla o se ha hablado una lengua-, percibiríamos que el territorio titulado es solamente una porción del total susceptible de ser, de alguna manera, reconocido como indígena.

4 Aunque una definición precisa solo es verdaderamente necesaria en un contexto jurídico y no descriptivo, entiendo por territorio étnico el espacio necesario para la supervivencia de un pueblo; y territorio histórico o tradicional el espacio máximo que un pueblo ha ocupado alguna vez en el pasado, según la historia o la arqueología que lo demuestra. Evidentemente, estas nociones merecerían ser tratadas con toda su complejidad aunque desbordaría el propósito de este artículo. En este sentido, véase el artículo de Richard Smith (2006b) para una reflexión sobre la diacronía en la territorialidad.

5 Comunicación personal de Pedro García Hierro. Para mayor información al respecto del estado de los territorios indígenas en América en general y Amazonía en particular, consultar la síntesis magistral de Alberto Chirif \& Pedro García Hierro (2007), donde se realiza un balance de las propuestas de la influyente obra anterior de Alberto Chirif et al. (1991). 
El otro gran problema del actual estado de cosas es que el reconocimiento jurídico de estos títulos de propiedad no es acompañado por sistemas de seguridad, capaces de garantizar el derecho territorial y el ejercicio de este derecho.

Es decir, los poderes públicos responsables de hacer respetar la ley para evitar el expolio de tierras y recursos, no actúan con la diligencia necesaria. Es en este punto donde las dudas son más que justificadas, porque (como veremos más adelante) no parece que la mentalidad de colonialismo interno inscrita en el genoma — por decirlo de alguna formadel Estado peruano, pueda cambiar ni con la ley que él mismo ha dictaminado en la mano. Lo que cambia es la propia ley, revisada en sucesivas ocasiones en perjuicio de los derechos de los pueblos indígenas. Se debe añadir que la progresiva penetración de la selva obliga a los indígenas a ceder soberanía por la presencia de colonos, pero también de muchos otros agentes e intereses, con sus respectivas estrategias espaciales, como las circunscripciones administrativas del Estado y los espacios de la empresa y el mercado. En este contexto de multiplicidad de legitimidades, los pueblos indígenas, sometidos a presiones políticas y económicas considerables, pueden perder el criterio y terminar entregando sus posesiones a lógicas de planificación y gestión territorial que acaben con la apropiación de su patrimonio, la depredación de los recursos naturales y en muchos casos con su disgregación y el éxodo fuera de su espacio territorial. Estos procesos ya se han dado, y tienen como resultado la mutación de las poblaciones indígenas: desde propietarios agrarios a pobres rurales, pasando a ocupar los cinturones de pobreza de núcleos urbanos y a engrosar el colectivo de pobres extremos.

En conclusión, la problemática de la legitimidad de los territorios de los pueblos indígenas no solo es una cuestión jurídica, como (quizás con demasiado optimismo) se ha pensado hasta hoy. Se trata de una cuestión, más que política, cultural; un tema relacionado con el modelo de sociedad que se quiere. Dicho de otra forma, iestá preparada la sociedad peruana para hacer respetar los derechos adquiridos de sus ciudadanos —aunque sean indígenas amazónicos- y refrendados tanto por la legalidad vigente como por un conjunto de jurisprudencia, convenios y declaraciones internacionales asumidas por el Perú? ¿La democracia será lo suficientemente sólida para evitar que grupos de poder continúen utilizando, para su propio beneficio, las prerrogativas que ofrece el Estado para la explotación de recursos naturales, en la más pura mentalidad colonial, sin importarle el precio en términos de convivencia social, conciencia democrática y decencia civil que esto implique?

\section{LA SELVA PARA EL ESTADO}

La respuesta a estas preguntas, a la luz de las diversas políticas que se están aplicando recientemente en el Perú, es negativa. El Estado está promoviendo una política favorable a grandes inversiones, especialmente en relación a la extracción de recursos naturales y en particular el petróleo, actividades extremadamente rentables en términos económicos para las arcas públicas, pero altamente perjudiciales para los pueblos indígenas que las acogen en sus territorios y que deben afrontar solos los costos de los impactos en la población y el medio ambiente. En el caso de las inversiones petroleras, por ejemplo, la expansión en estos dos últimos años ha sido enorme si la comparamos con lo sucedido en países vecinos. Hoy tenemos 180 lotes (superficies licitadas por el Estado para la exploración y explotación de petróleo y gas) en toda la Amazonía occidental, con más de 35 compañías multinacionales trabajando. Estos lotes se encuentran en todos los países andinos pero con una cantidad y extensión variable. En Colombia, Bolivia (e incluso en el Brasil occidental) 
son poco importantes, aunque existen indicios que esto puede estar cambiado. Desde el año 2003, en Perú se ha promovido la inversión con una política fiscal favorable y se ha producido un nuevo boom petrolero, incrementado a partir de 2005. En estos momentos hay 48 lotes activos en la Amazonía peruana con contratos con empresas multinacionales, lo que significa en términos comparativos que el $70 \%$ de superficies concedidas para la exploración y/o explotación petrolera en toda la cuenca amazónica es territorio peruano (cuadro 1).

Cuadro 1 - Áreas concedidas para actividades de exploración y explotación hidrocarburífera (2007)

\begin{tabular}{|c|c|c|c|}
\hline & & (Hectáreas) & $\%$ \\
\hline \multirow{3}{*}{ Bolivia } & Exploración & 2978495 & 6 \\
\hline & Exploración & 0 & 0 \\
\hline & Total & 2978495 & 6 \\
\hline \multirow[t]{3}{*}{ Brasil } & Exploración & 5700000 & 11 \\
\hline & Exploración & 1000000 & 2 \\
\hline & Total & 6700000 & 13 \\
\hline \multirow[t]{3}{*}{ Colombia } & Exploración & 781751 & 1 \\
\hline & Exploración & 174426 & 0 \\
\hline & Total & 956177 & 2 \\
\hline \multirow[t]{3}{*}{ Ecuador } & Exploración & n.d. & - \\
\hline & Exploración & 5000000 & 10 \\
\hline & Total & 5000000 & 10 \\
\hline \multirow[t]{3}{*}{ Perú } & Exploración & 35214244 & 67 \\
\hline & Exploración & 1723710 & 3 \\
\hline & Total & 36937954 & 70 \\
\hline \multirow[t]{3}{*}{ Total Cuenca Amazónica } & Exploración & 44674490 & 85 \\
\hline & Exploración & 7898136 & 15 \\
\hline & Total & 52572626 & 100 \\
\hline
\end{tabular}

Fuente: Campodónico (2008)

El gobierno ha licitado todos los bloques posibles menos 8. Unos 16 bloques más, como mínimo, serán concedidos antes de finalizar el año 2008. Los 64 bloques licitados actualmente cubren el $72 \%$ de la Amazonía peruana (490 $\left.000 \mathrm{~km}^{2}\right)$, cuando en 2005 cubrían solo el $15 \%$. Solamente los parques nacionales (menos de un $12 \%$ ) se libran por el momento. Sin embargo, 20 lotes se superponen a 11 áreas de protección menor (reservas comunales y zonas reservadas) y 58 de los 64 lotes se sobreponen a territorios titulados de comunidades nativas. Otros 17 lotes se yuxtaponen a áreas que han sido propuestas como territorios para grupos indígenas en aislamiento voluntario. Esto sucede en el área de la Amazonía más rica en biodiversidad, es decir, en una de las regiones más ricas en el planeta y por lo tanto, el verdadero patrimonio del Perú (fig. 1)6.

En este contexto de políticas agresivas de inversiones para la extracción de recursos naturales como el petróleo, los títulos comunales de los que disponen los pueblos indígenas no solo no sirven de mucho — recordemos que de todas maneras la propiedad del subsuelo es en

6 Para más datos, ver Finer et al. (2008) y Campodónico (2008). Para un informe pormenorizado de las consecuencias que puede representar para los indígenas una campaña de exploración petrolera a partir de un estudio de caso, ver Surrallés $(2007 ; 2008)$. 


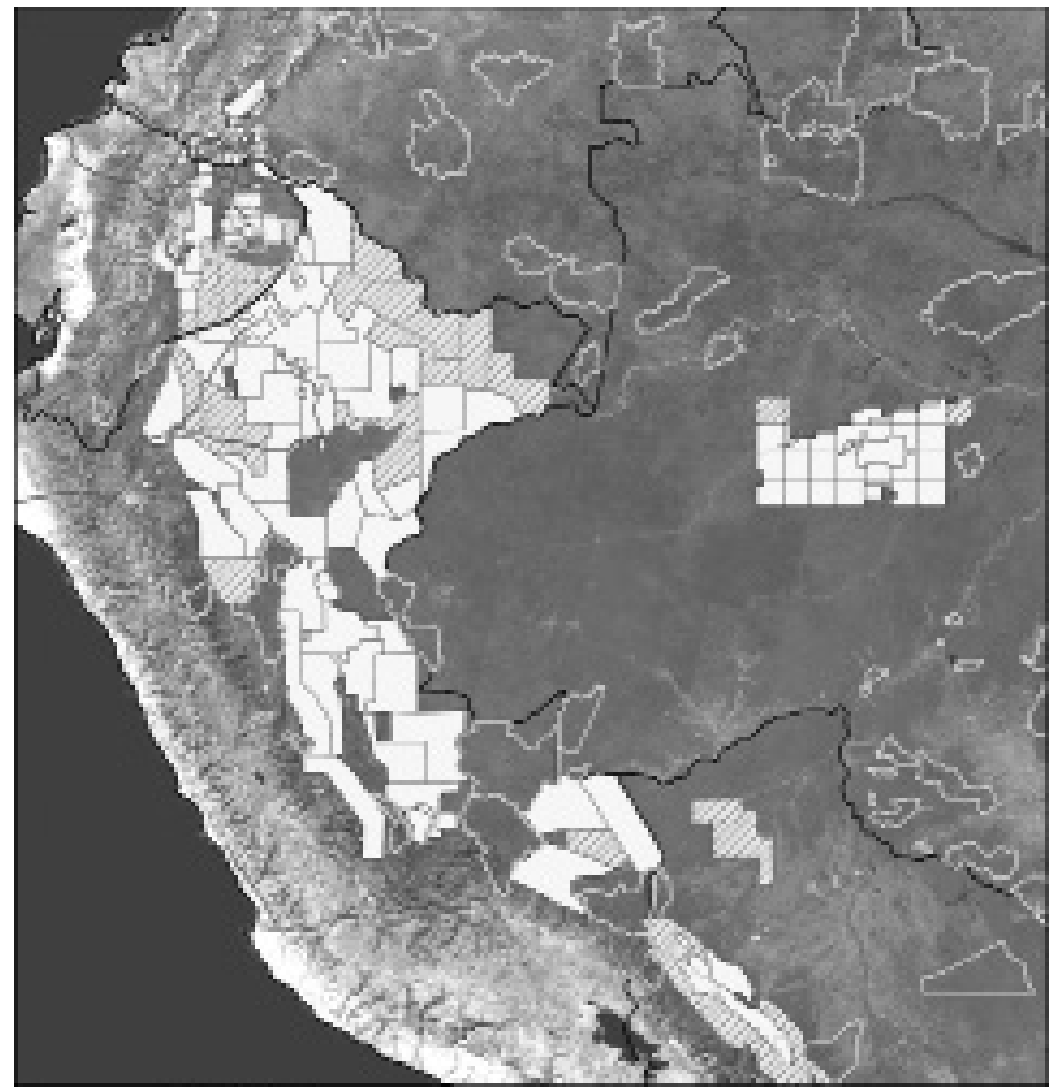

Lotes petroleros
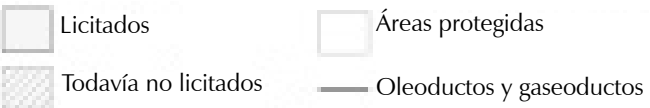

Figura 1 - Lotes petroleros en la Amazonía occidental

Fuente: Finer et al. (2008)

el Perú propiedad del Estado-, sino que incluso pueden ser contraproducentes. Por la actuación de los poderes públicos en algunos casos, parece que se quiera aprovechar el hecho de que las tierras están legalmente tituladas a nombre de comunidades indígenas para deshacerse de ciertas responsabilidades en el seguimiento de las operaciones, en la aplicación de la legalidad vigente en los procedimientos y en la debida protección de la población local afectada. A esto se le puede añadir que las comunidades indígenas, sometidas a presiones intensas y con una escasa capacidad de negociación, se encuentran a menudo frente a la política de los hechos consumados por parte de la compañía petrolera específica, incumpliendo esta obligación de consulta previa estipulada por el Convenio 169 de la OIT. Aunque siempre legalmente avalada por la farsa de los llamados estudios de impacto ambiental y social, financiados por ella misma y realizados por empresas, sin ninguna independencia, especializadas en este tipo de exámenes. El dilema no es entre las organizaciones indígenas que están a favor o en contra de las actividades petroleras en sus territorios — como se asegura a veces con dudosa intención—, sino entre las que cederán 
a cambio de unas contraprestaciones o las que mantendrán una política de resistencia. En cualquier caso, dadas las condiciones en que se otorgan los licencias petroleras en el momento de la licitación de los lotes y la corrupción que — ahora se sabe fehacientementeimpera entre los altos funcionarios encargados, la responsabilidad fiscalizadora del Estado sobre las actividades empresariales que se realizan en sus concesiones, será débil o nula. Esta corrupción, que afecta a las esferas más altas del poder, según se desprende de la notas de prensa al respecto, puede asimismo explicar la velocidad inusitada en que se han subastado los lotes petroleros en estos últimos años ${ }^{7}$.

\section{LOS PUEBLOS INDÍGENAS Y SU INTEGRACIÓN DEFRAUDADA}

El trabajo de titulación al amparo de la Ley de Comunidades Nativas y Campesinas, realizado desde la década de 1970, también ha conseguido generar un movimiento indígena. El proceso se podría resumir de la siguiente manera: las titulaciones eran precedidas por un trabajo de información que los dirigentes indígenas —al principio integrados a la dependencia del Estado creada para la titulación, el SINAMOS, y después como representantes de organizaciones independientes - realizaban con los diferentes grupos, a veces con contactos muy esporádicos con la sociedad nacional. Formalizada la titulación, se elegían los representantes comunales, Apus, llamados también Tenientes Gobernadores. Con esta perspectiva integracionista que presidía la ley, se decía (sin ironía) que estas autoridades elegidas por la asamblea de comuneros eran la representación del Estado en la zona y las comunidades como una unidad administrativa subdistrital.

Después de la titulación y con una intensidad desigual según las regiones, las comunidades recién formadas se asociaban formando una federación en base a criterios étnicos y espaciales, en general, una cuenca. Así florecieron, sobre todo en la década de 1980, las federaciones indígenas en toda la Amazonía y así surgió la más significativa federación de federaciones, la AIDESEP. El trabajo de titulación fue acompañado por toda una serie de iniciativas con miras a fomentar la integración de los pobladores indígenas a la ciudadanía, una forma de promover el desarrollo en estas tierras abandonadas por la administración pública. Entre todas estas iniciativas, las que tuvieron quizás una mayor repercusión, especialmente en regiones de la selva norte, fueron las campañas para proveer de libretas electorales — que muy pocos indígenas poseían a principios de 1990-. En Lima, en aquellos tiempos, el tono marcial de los discursos contra las pretensiones ecuatorianas se elevaba, el ejército se posicionaba en bases estratégicamente determinadas en la zona, la diplomacia se agitaba, pero a nadie se le había ocurrido que una forma de legitimar las fronteras de un Estado es facilitar el ejercicio de los derechos cívicos a los habitantes del lugar. Años después de estas campañas, los indígenas empezaron a ser elegidos, primero a nivel distrital, y después a nivel provincial, disponiendo actualmente de muchas alcaldías a este nivel de la administración. En todo caso, la voluntad de una integración al Estado, según la visión pragmática propia de las organizaciones indígenas surgidas de este proceso de titulación, fue evidente cuando se convirtieron en un factor de estabilidad, un cuerpo de interposición y de promoción de la paz y la democracia en muchas de las zonas del país, entonces asoladas por la violencia. La memoria política es muy corta (o el cinismo desmesurado) cuando oímos hoy a los responsables políticos del mismo partido que

7 Fernando Rospigliosi, ex ministro del Interior del Perú, reveló unos audios que dan cuenta de un caso flagrante de corrupción en las licitaciones de pozos petrolíferos entre la empresa estatal Perú-Petro y la compañía noruega Discover Petroleum. El ex ministro añadió al día siguiente no tener dudas de que existan otros casos parecidos en otras licitaciones (El Comercio, 06/10/2008). 
gobernaba entonces acusar a las organizaciones indígenas, en general, y a la AIDESPEP, en particular, de violentos por los incidentes acaecidos estos últimos meses a raíz de las protestas contra la llamada «ley de la selva».

En su primera versión, la Ley de Comunidades Nativas y Campesinas permitía el derecho inalienable a la propiedad colectiva de los grupos de indígenas. Desde entonces, la legislación internacional se ha ido desarrollando con una gruesa jurisprudencia y un buen número de tratados y declaraciones firmados por el Perú. Sin embargo, como afectada por una esquizofrenia, la legislación nacional peruana ha intentado erosionar en sucesivas ocasiones los pocos derechos territoriales que proclama la Ley de Comunidades Nativas y Campesinas. Fujimori consiguió eliminar la calidad de intangibilidad de las tierras. Alan García, en concordancia con esta voluntad de eliminar obstáculos para las grandes inversiones internacionales de empresas extractivas, ha intentado continuar en esta dirección con los famosos decretos legislativos 1015 y 1073, que han levantado a todo los pueblos amazónicos indígenas y no indígenas hasta conseguir — como ya he mencionado- que el Congreso se abstuviera de ratificarla infligiendo un revés sin precedentes al ejecutivo.

La situación resultante es un conflicto de intereses inevitable y veremos (de seguir así) un proceso conflictivo, largo y políticamente muy intenso. Es, en realidad, el resultado de la colisión de dos inercias históricas de más de tres decenios de antigüedad. Por un lado el Estado peruano acepta desdeñosamente legitimar los derechos territoriales pero, profundamente impregnado de la idea ya lanzada por Belaunde en la década de 1960 de la Amazonía como el granero del Perú, y otras propuestas de un colonialismo interno impropio de una democracia, erosiona desde los años 1990 el espíritu de la ley de comunidades con decretos e iniciativas que facilitan las inversiones de la industria extractiva.

Por otro lado, las organizaciones indígenas en el Perú se crean y desarrollan en el proceso mismo de titulación de las comunidades. Los indígenas encuentran en las comunidades su inscripción en la sociedad peruana, la satisfacción parcial pero real al reclamo histórico de sus derechos territoriales y una garantía de supervivencia. Para ellos las comunidades no son un bien inmueble, son su condición de existencia, al menos en buena parte de la Amazonía. Debemos recordar que la Ley de Comunidades Nativas y Campesinas es una ley que no busca ofrecer reparación a los pueblos indígenas por una política de Estado que les ha perjudicado históricamente, tal y como (actualmente) se decanta la jurisprudencia multilateral en esta área. En los años y en las condiciones políticas en que esta ley se promulgó, desde una visión estatalista de izquierdas, el objetivo era integrar las poblaciones indígenas a la sociedad peruana, junto con los obreros y campesinos, para contribuir al desarrollo de su base popular: se trataba en efecto de una ley integracionista. Los indígenas tomaron la palabra del Estado y se convencieron de que a través de las comunidades podrían acceder al estatuto de ciudadanos.

Las organizaciones indígenas que representan en el Perú a cientos de comunidades agrupadas en federaciones étnicas que recubren toda la franja amazónica, a su vez agrupadas en instancias regionales y nacionales, se autogeneraron en un momento muy diferente del actual. Hace un par de decenios, insisto, se trataba de titular unas tierras a las que el Estado, a desgana, accedía por considerar marginales. Era también la época en que estas organizaciones proveían a los indígenas de una legalidad y acceso a sus derechos ciudadanos que el Estado — por ineficacia en el mejor de los casos, o por una voluntad de mantenerlos al margen - no se dignaba a proporcionar. La pregunta es si estas organizaciones nacidas con la voluntad de incorporarse a la ciudadanía sabrán transformarse en organizaciones de defensa frente al propio Estado al que, hasta ahora, veían como su garante para la integración. Es decir, estas organizaciones żsabrán mutar lo suficiente para hacer frente al nuevo capítulo que se está abriendo de relación con la administración y, de no ser así, cómo se desarrollarán los acontecimientos? ¿O preferirán la línea, desarrollada en los países 
andinos vecinos, de aliarse con un grupo heterogéneo de movimientos sociales con el fin de participar en un proceso de acceso al poder estatal, con el riesgo de perder de vista los objetivos de autonomía territorial y desarrollo adaptado en que se han forjado?

Con el desenlace de las protestas contra los decretos legislativos 1015 y 1073 promovidos por el segundo mandato de Alan García, el movimiento indígena accede a la política nacional peruana, con mucho retraso en comparación con otros países del entorno. A diferencia de éstos, lo indígena ha entrado por la puerta trasera, como no podía ser de otro modo en un país que vive de espaldas a la selva y donde la sierra ha sido incapaz de articular un discurso audible en este sentido, oprimida por el peso de fantasmas de pasados gloriosos y nociones ajenas a toda realidad. En todo caso, una oportunidad se presenta con estos acontecimientos (quizás la última) para profundizar en la democracia, dando cabida a estas sensibilidades plurales que emergen como actores políticos. Si esta oportunidad no se aprovecha y el diálogo se cierra por prejuicios ideológicos o por querer ignorar una situación irreversible, no será entonces la democracia que se fortalecerá sino la incertidumbre de dejar en manos de posiciones polarizadas el devenir del país.

\section{LA LEGISLACIÓN Y EL FUTURO DE LOS DERECHOS}

Lo más interesante es que esta situación sucede cuando, a nivel jurídico, los pueblos indígenas nunca han estado mejor dotados para defender sus intereses. Contra la opinión de los Estados que consideran que tienen derecho a la gestión de los recursos naturales por una razón de interés público, los indígenas consideran que sus derechos sobre el territorio obligan a dar su consentimiento libre, previo e informado. Puesto que ya no se trata solamente de ser consultados como obliga el convenio 169 de la OIT y las propias legislaciones nacionales (en Ecuador y Perú, por ejemplo). En efecto, los últimos instrumentos internacionales indican que sí podrían tener derecho a veto. En 2007 la Corte Interamericana de Derechos humanos sentó jurisprudencia con el caso del pueblo Saramaka versus Surinam, estatuando que el Estado debe garantizar el derecho a los pueblos indígenas a aceptar o no proyectos que afecten a sus territorios.

Por otro lado, el 13 de septiembre de 2007, la Asamblea General de las Naciones Unidas, órgano supremo del sistema de las Naciones Unidas y por lo tanto del derecho internacional, adoptó con una mayoría aplastante de 143 votos a favor y solo 4 en contra (Canadá, Australia, Nueva Zelanda y Estados Unidos) y 11 abstenciones, la Declaración sobre los Derechos de los Pueblos Indígenas. Se trata, nada más y nada menos, de una declaración del mismo nivel que la célebre Declaración Universal de los Derechos Humanos, que consagra los derechos especiales, pero con un alcance igualmente universal, de estas colectividades llamadas pueblos indígenas.

La Declaración, que representa el resultado de años de intensas negociaciones entre los Estados miembros, los representantes de los pueblos indígenas y las organizaciones de derechos humanos, no hace más que recoger un consenso internacional cada vez más extendido en torno al contenido de los derechos indígenas. Estos vienen siendo progresivamente reconocidos en numerosos países, promovidos por diversos instrumentos internacionales, en particular por el Convenio 169 de la Organización Internacional del Trabajo, y por el ejercicio de las instituciones internacionales de derechos humanos. En resumen, la Declaración recoge los derechos reconocidos anteriormente a nivel internacional que los indígenas, en lo individual y colectivamente, disponen y nota asimismo las circunstancias especiales de su existencia como pueblos discriminados y despojados de sus recursos ancestrales durante largo tiempo, por las cuales requieren una atención particular de los Estados y de la comunidad internacional. 
La Declaración consta de un preámbulo y de 46 artículos. En el preámbulo se afirma, entre otras cosas, que los pueblos indígenas son iguales a todos los demás pueblos y que por la tanto, tienen derecho a ser diferentes, a considerarse a sí mismos diferentes y a ser respetados como tales. Esta diversidad cultural humana es parte del gran patrimonio común de la humanidad del que debemos, como humanos, sentirnos orgullosos. Las ideologías y prácticas que propugnan algún tipo de supremacía de unos pueblos sobre otros, como se ha dado durante el periodo colonial, deben ser consideradas como racistas, sin ninguna base científica, ética o jurídica. Los pueblos indígenas han sido y siguen siendo, sin embargo, víctimas de tales doctrinas, que les ha llevado a ser objeto de grandes injusticias históricas, como las de haber sido desposeídos de sus tierras, cultura y recursos. Estas situaciones de discriminación les han impedido ejercer su derecho al desarrollo según sus propias necesidades e intereses, añadiendo al expolio material que han sufrido, o quizá por esto mismo, el desprecio de su patrimonio cultural. Estas circunstancias, según la asamblea, hacen urgente la necesidad de respetar y promover los derechos intrínsecos de los pueblos indígenas, que derivan de sus estructuras políticas, económicas y sociales y de sus culturas, de sus tradiciones espirituales, de su historia y de su filosofía, especialmente los derechos a sus tierras, territorios y recursos. Ello lleva a recordar la importancia fundamental del derecho de todos los pueblos a la libre determinación, en virtud del cual éstos determinan libremente su condición política y persiguen libremente su desarrollo económico, social y cultural. Los Estados a los que pertenecen deben ofrecer arreglos constructivos a las variadas situaciones en las que se encuentran los indígenas, en aras a su desarrollo, tanto económico como cultural, en el respeto de sus convicciones como pueblos. Y más allá de los Estados, el preámbulo finaliza declarando la responsabilidad de la propia organización de las Naciones Unidas en el seguimiento de la situación de los pueblos indígenas y el desarrollo a los derechos colectivos que disfrutan como tales.

En el articulado se desarrollan estas ideas apuntadas en el preámbulo. Empieza con la reafirmación de los derechos básicos individuales para enunciar el derecho colectivo a la libre determinación como pueblos indígenas. Sigue abordando los derechos a su patrimonio cultural y a una educación adaptada a su cultura y particularidades lingüísticas así como a la protección de niños, ancianos y personas desvalidas. Continua con el derecho al propio desarrollo, a la salud con respeto a sus convicciones culturales en un territorio seguro y un medio ambiente sano. Los criterios colectivos que fijen los principios de su identidad, pertenencia, instituciones políticas de representación y relaciones exteriores con Estados, entes multilaterales o agencias internacionales de cooperación como pueblos, deben ser también respetados. La Declaración termina fijando la responsabilidad de las Naciones Unidas y de sus órganos en el seguimiento del cumplimiento de estas disposiciones y advierte que los límites de la aplicación de estos derechos son el propio ordenamiento jurídico internacional con el principio de soberanía del Estado en primer lugar, la carta de la Naciones Unidas y los derechos humanos. Una lectura permite distinguir cuatro tipos de enunciados relevantes, que examinaré prestando atención a los asuntos territoriales.

\section{1. Los artículos que reafirman los derechos elementales para los pueblos indígenas}

En efecto, muchos de los artículos reafirman derechos básicos, insistencia comprensible dadas las situaciones de discriminación que sufren especialmente los pueblos indígenas. Por ejemplo el derecho, como pueblos o como individuos, al disfrute pleno de todos los derechos humanos y las libertades fundamentales reconocidos en la Carta de las Naciones 
Unidas, la Declaración Universal de Derechos Humanos y las normas internacionales de derechos humanos, como versa el Artículo primero. Otros artículos van en el mismo sentido con proclamas al derecho a no ser discriminados por su origen, a tener una nacionalidad y no mantenerlos en limbos jurídicos (como a menudo sucede en zonas fronterizas), a gozar de su integridad física, paz y libertad sin ser sometidos a desplazamientos, agresiones, esterilizaciones y otras acciones que están ocurriendo o que se han dando recientemente. El articulado sigue con un buen número de aspiraciones elementales de todo ser humano.

\section{2. Los artículos que proponen el desarrollo de derechos colectivos}

Aparte de este tipo de párrafos, encontramos también algunos artículos que proclaman derechos en positivo, es decir, que no solo garantizan el cumplimiento de los derechos fundamentales, sino que se aventuran en derechos específicos que los pueblos indígenas tienen como colectivo. Los más importantes en esta categoría son, sin duda, los artículos 3 , 4 y 5 , donde se proclama que los pueblos indígenas tienen derecho a la libre determinación que deriva en la libre determinación de su condición política y de su desarrollo económico, social y cultural. Es así como los pueblos indígenas, en ejercicio de su derecho a la libre determinación, tienen derecho a la autonomía o al autogobierno en las cuestiones relacionadas con asuntos internos y locales, así como a disponer de medios para financiar sus funciones autónomas; sin perjuicio de su derecho como ciudadanos a participar plenamente, si lo desean, en la vida política, económica, social y cultural del Estado. En el ámbito de los derechos territoriales que nos ocupa, la Declaración postula en una serie de artículos (del 25 al 27) el derecho de los indígenas a mantener y fortalecer su propia relación espiritual con las tierras, territorios, aguas, mares costeros y otros recursos que tradicionalmente han poseído u ocupado y utilizado. Esto implica que tienen derecho a las tierras, territorios y recursos que tradicionalmente han poseído, ocupado, utilizado o adquirido en el pasado y a poseer, utilizar, desarrollar y controlar las tierras, territorios y recursos que poseen, en razón de la propiedad tradicional u otro tipo tradicional de ocupación o utilización, así como aquellos que hayan adquirido de otra forma. La declaración insta a los Estados a establecer y aplicar, conjuntamente con los pueblos indígenas, un proceso equitativo, independiente, imparcial, abierto y transparente, en el que se reconozcan debidamente las leyes, tradiciones, costumbres y sistemas de tenencia de la tierra de los pueblos indígenas, para reconocer y adjudicar los derechos de los pueblos indígenas en relación con sus tierras, territorios y recursos, comprendidos aquellos que tradicionalmente han poseído, ocupado o utilizado. Además del derecho territorial, la Declaración recoge otros aspectos directamente relacionados en artículos posteriores como los referentes al derecho a un medio ambiente protegido, desmilitarizado y a la protección del patrimonio cultural que se deriva de la relación con el entorno.

\section{3. Los que instan al Estado a ofrecer reparación}

Otros artículos exhortan a los Estados cuyas fronteras incluyen pueblos indígenas, a no solo velar por el respeto de estos derechos fundamentales, sino a promover acciones que favorezcan su dignidad en la diversidad así como su autonomía con consultas adecuadas y de buena fe cuando se puedan ver afectados por actividades en sus territorios o localidades. En el ámbito de las obligaciones que se imponen a los Estados, la declaración no se contenta con allanar el futuro. Propone además políticas de reparación para 
compensar los perjuicios que los pueblos indígenas han sufrido con anterioridad o para las circunstancias futuras donde sea necesario un desagravio. Destacan, en este campo, el artículo 11.2 donde, se insta a los Estados a proporcionar reparación por medio de mecanismos eficaces, que podrán incluir la restitución, establecidos conjuntamente con los pueblos indígenas, respecto a los bienes culturales, intelectuales, religiosos y espirituales de que hayan sido privados sin su consentimiento libre, previo e informado o en violación de sus leyes, tradiciones y costumbres. La reparación es exigida asimismo en temas territoriales. Así se exige al Estado (artículo 28) la restitución —cuando ello no sea posible, una indemnización justa y equitativa- de las tierras, los territorios y los recursos que tradicionalmente hayan poseído, ocupado o utilizado y que hayan sido confiscados, tomados, ocupados, utilizados o dañados sin su consentimiento libre, previo e informado. Especifica además que salvo que los pueblos interesados hayan convenido libremente en otra cosa, la indemnización consistirá en tierras, territorios y recursos de igual calidad, extensión y condición jurídica o en una indemnización monetaria u otra reparación adecuada. También es importante, en este sentido, el artículo 32.3, donde exige reparación justa y equitativa por las actividades que afecten a sus tierras o territorios y otros recursos, particularmente en relación con el desarrollo, la utilización o la explotación de recursos minerales, hídricos o de otro tipo, para mitigar las consecuencias nocivas de orden ambiental, económico, social, cultural o espiritual sin por ello dejar de celebrar las consultas de buena fe a través de las instituciones indígenas representativas antes de aprobar cualquier proyecto.

\section{4. Los artículos que delimitan el perímetro del ejercicio de estos derechos}

Una cuarta categoría de artículos fija, en la parte final de la Declaración, los límites de estos derechos. Encontramos por supuesto los límites impuestos por la Declaración de los Derechos Humanos, que en su artículo primero afirma la igualdad ante la ley de toda persona y que, de alguna forma, cuestiona los derechos colectivos que inspiran esta declaración. Asimismo, en el último artículo, el 46, se afirma que nada de lo contenido en la Declaración se puede interpretar en el sentido de que confiere a un Estado, pueblo, grupo o persona derecho alguno a participar en una actividad o realizar un acto contrario a la Carta de las Naciones Unidas, es decir a los Estados que forman parte de esta organización y que son los mismos que firman la Declaración. Esto se subraya cuando se afirma que la Declaración no autoriza ni alienta de ningún modo acción alguna encaminada a quebrantar o menoscabar, total o parcialmente, la integridad territorial o la unidad política de Estados soberanos e independientes.

En definitiva, a pesar de que la Declaración debe ser solo el principio de un suceso, representa sin lugar a dudas el instrumento más importante, dinámico y profundo de entre los existentes en las normas internacionales en vigor. Tampoco quisiera parecer ingenuo: una declaración es lo que es. Hay que esperar que aparezcan las convenciones y los tratados derivados, que sí son vinculantes, para ver como los países interpretan esta carta fundamental y si quieren aprovechar de su último artículo para traicionar el espíritu del conjunto del texto. En todo caso, con la parsimonia necesaria de parte de los pueblos indígenas, se puede afirmar que la proclama del derecho a la libre determinación que expresa sin ambigüedad, sumada a la importancia que se da al territorio como derecho fundamental, esta declaración ofrece toda una serie de posibilidades novedosas que intentaremos sintetizar a modo de conclusión. 


\section{CONCLUSIÓN: LA DECLARACIÓN, LOS TERRITORIOS INDÍGENAS Y LA ANTROPOLOGÍA POR VENIR:}

El elemento de derecho más importante de la Declaración es la libre determinación de los pueblos indígenas, que formula de manera explícita. La libre determinación permite a los pueblos -indígenas o no- determinar libremente su condición política y su sistema de representación, y en lo que concierne al territorio, que según la declaración es el territorio tradicional que han poseído, a disponer libremente de sus recursos y de utilizarlos de acuerdo con sus prácticas, sistemas de tenencia y normas internas. Ahora bien, la posibilidad de que los Estados promuevan la libre determinación de los pueblos indígenas que albergan, tal y como es formulada por la Declaración, es todavía muy lejana. Por esta razón, los pueblos indígenas deberían empezar, en el Perú o en cualquier país donde se encuentren, a tomar iniciativas de cara a determinar su territorialidad, los límites de su territorio y su condición política. No conviene esencializar la dualidad pueblo-territorio, de difícil aplicación en algunos casos, siempre compleja y controvertida, pero es indiscutible que puede ser un recurso útil en muchos casos y la reflexión antropológica puede ayudar a esclarecer sus alcances y límites. En efecto, este tipo de procesos pueden crear herramientas de primera importancia para proteger y reivindicar, más allá de las políticas estatales del gobierno de turno, un derecho territorial. Una manera de no depender de una relación exclusiva con un Estado, con un gobierno enfrascado en sus posiciones y hermético a toda propuesta (como sucede ahora en el Perú). Esto no quiere decir, por supuesto, que las formas de territorialidad legitimadas por el Estado, en el caso del Perú, las Comunidades indígenas reconocidas por la Ley de Comunidades Nativas y Campesinas, no deban seguir siendo piezas clave del dispositivo de defensa territorial indígena, intentando seguir con la ampliación de espacios y el desarrollo de la ley en el buen sentido, por medio de la presión política y la negociación.

Autoconstituirse como pueblo indígena, definir el territorio, pactarlo con los pueblos y otros colectivos concernidos, determinar el tipo de titularidad a la que se acogen y regular la forma de gobierno territorial es practicar la libre determinación, una tarea que compete a cada pueblo indígena que quiera acogerse a esta declaración. Lograr el reconocimiento del Estado nacional y de la comunidad internacional es un objetivo que debe alcanzar el movimiento indígena, es decir, las organizaciones representativas, de nivel regional, nacional e internacional, con el apoyo de las diversas instituciones que, en el derecho internacional, vigilan la aplicación y desarrollo de los derechos fundamentales enunciados por la organización de las Naciones Unidas. Formalizar este ejercicio de autodeterminación y difundirlo hasta su reconocimiento final puede ser uno de los objetivos políticos de mayor relevancia para las organizaciones indígenas en los próximos años, para el que la antropología tiene mucho que ofrecer. En otras palabras, si se llega a un conflicto de intereses con una compañía extractora, por ejemplo, y se debe apelar a esta Declaración, conviene que, antes de que esto suceda, los pueblos indígenas se hayan expresamente autodeclarado como tales por medio de un memorando, añadiendo toda la información histórica y antropológica que lo demuestre. En el caso de que un pueblo indígena no disponga de un trabajo antropológico monográfico debería promoverlo de alguna manera. La antropología, vista a veces con desconfianza por los pueblos indígenas, puede en esta coyuntura ser un instrumento muy útil para demostrar la realidad de la existencia de un

8 En estas conclusiones sobre todo, pero también en otras partes del texto, avanzo los resultados de un trabajo más amplio y profundo sobre estos temas en curso, escrito junto a Pedro García Hierro, titulado provisionalmente Antropología de un derecho. 
pueblo indígena por la conformidad establecida por la comunidad científica concernida por estos asuntos. Sin perder, por supuesto, su independencia de criterio, visión crítica y distancia objetiva que son la garantía de su fiabilidad, nuestra disciplina debería implicarse en este tipo de procesos. Con la finalidad de demostrar la existencia del pueblo indígena y su relación histórica con un espacio territorial es muy importante detallar en la medida de lo posible toda la densidad de relaciones entre los elementos del patrimonio cultural inmaterial y su localización precisa en el mapa. Esto puede demostrar la existencia de lugares de importancia simbólica, de manera que se refuerce su intangibilidad antes de confrontar un conflicto de intereses y no durante o después. Esta ubicación de los elementos de la cultura inmaterial también puede, a través de la historia oral o de los mitos, determinar puntos en el mapa de importancia en el pasado y trazar así los límites del territorio en otros tiempos históricos que permita, si las condiciones se presentan, reclamar una restitución o como mínimo una compensación. Una difusión adecuada de los memoranda y la documentación antropológica e histórica que sustenten la autoidentificación será muy importante para tomar la iniciativa en posibles litigios territoriales.

Derivado de lo anterior, otro proyecto de largo alcance, para el que la antropología dispone de un arsenal conceptual considerable, es ampliar lo que se entiende por territorio a partir de la experiencia y la percepción indígena del entorno, de la historia y de la sociedad. Porque limitarse a pensar que el territorio es una simple superficie de tierra que alberga un pueblo y le ofrece los recursos necesarios para la subsistencia es, hoy en día, una perspectiva obsoleta, producto de la proyección de la idea de propiedad agrícola sobre unas realidades culturales que poca relación pueden tener con una tradición de ocupación del espacio y su jurisprudencia correspondiente surgida en las orillas del Mediterráneo, antes de la colonización europea de América. Este trabajo es muy útil para una aplicación de la legislación que tenga en cuenta las necesidades expresadas por las propias poblaciones a partir de unos valores que solo pueden ser definidos culturalmente por ellas mismas.

En todos estos campos, sobra decirlo, la antropología tiene mucho que reflexionar, decir y ofrecer con el objetivo de establecer puentes entre, por un lado, unos derechos que sin ser óptimos son muy avanzados pero completamente abstractos y de difícil aplicación y, por otro lado, unas realidades que, como la explotación del petróleo en la Amazonía peruana, se resisten tenazmente a toda posibilidad de ejercicio de este derecho. La antropología, por asociar como disciplina una reflexión fundamental sobre la diversidad cultural con una experiencia concreta de situaciones sobre el terreno, está bien preparada para esta labor de acercar el derecho, o el deseo, a la realidad.

\section{Referencias citadas}

CAMPODÓNICO, H., 2008 - Amazonía y explotación petrolera. La República, 17/10/08. CHIRIF, A. \& GARCÍA HIERRO, P., 2007 - Marcando Territorio. Progresos y limitaciones de la titulación de territorios indígenas en la Amazonía, 340 pp.; Copenhague: IWGIA.

CHIRIF, A., GARCÍA HIERRO, P. \& CHASE SMITH, R., 1991 - El indígena y su territorio son uno solo. Estrategias para la defensa de los pueblos y territorio indígenas en la cuenca amazónica, 214 pp.; Lima: OXFAM América, Coordinadora de las Organizaciones Indígenas de la Cuenca Amazónica (COICA). 
FINER, M., JENKINS, C. N., PIMM, S. L., KEANE, B. \& ROSS, C., 2008 - Oil and Gas Projects in the Western Amazon: Threats to Wilderness, Biodiversity, and Indigenous Peoples. PLoS ONE, 3 (8): e2932. doi:10.1371/journal.pone.0002932.

SMITH, R. C., 2006a - Where our ancestors once tread: Amuesha territoriality and sacred landscape in the andean Amazon of central Peru. In : Être indien dans les Amériques (C. Gros \& M.-C. Strigler, eds.): 69-84; París: Institut des Amériques.

SMITH, R. C., 2006b - Por dónde caminaban nuestros ancestros: mapeando el paisaje sagrado del pueblo Yanesha. In: Atlas de comunidades nativas de la selva central (Margarita Benavides, ed.): 23-25; Lima: Instituto del Bien Común.

SURRALLÉS, A., 2007 - Los Candoshi. In: Guía etnográfica de la Alta Amazonía (F. Santos \& F. Barclay, eds.), vol. VI: 358-372; Lima/Panamá: IFEA, Smithsonian Institution.

SURRALlÉS, A., 2008 - Kushilia 1993. Argumentos del Instituto de Estudios Peruanos, (2) 4; Lima: IEP. Revista digital.

SURRALLÉS, A. \& GARCÍA HIERRO, P. (eds.), 2004 - Tierra adentro. Territorio indígena y percepción del entorno, 307 pp.; Copenhague: IWGIA. 